\title{
Expression of Mouse Apolipoprotein SAA1.1 in CE/J Mice: Isoform-Specific Effects on Amyloidogenesis
}

\author{
Jin Yu, Hong Zhu, Jun-tao Guo, Frederick C. de Beer, and Mark S. Kindy \\ Departments of Biochemistry (JY, HZ, JTG, MSK) and Medicine (FCD) and the Stroke Program of the Sanders- \\ Brown Center on Aging (MSK), University of Kentucky, and the Veterans Affairs Medical Center (MSK), Lexington, \\ Kentucky
}

SUMMARY: Amyloid $A(A A)$ amyloid deposition in mice is dependent upon isoform-specific effects of the serum amyloid $A$ (SAA) protein. In type A mice, SAA1.1 and SAA2.1 are the major apolipoprotein-SAA isoforms found on high-density lipoproteins. During inflammation, both isoforms are increased 1000-fold, but only SAA1.1 is selectively deposited into amyloid fibrils. Previous studies showed that the CE/J mouse strain is resistant to amyloid induction. This resistance is not due to a deficiency in SAA synthesis, but is probably related to the unusual SAA isoform present. The CE/J mouse has a single acute-phase SAA protein (SAA2.2), which is a composite of the SAA1.1 and SAA2.1, with an amino terminus similar to the nonamyloidogenic SAA2.1. Recently, genetic experiments suggested that the SAA2.2 isoform might provide protection from amyloid deposition. To determine the amyloidogenic potential of the CE/J mouse, we generated SAA adenoviral vectors to express the various isoforms in vitro and in vivo. Purified recombinant SAA proteins demonstrated that SAA1.1 was fibrillogenic in vitro, whereas SAA2.2 was unable to form fibrils. Incubation of increasing concentrations of the nonamyloidogenic SAA2.2 protein with the amyloidogenic SAA1.1 did not inhibit the fibrillogenic nature of SAA1.1, or alter its ability to form extensive fibrils. Injection of the mouse SAA1.1 or SAA2.2 adenoviral vectors into mice resulted in isoform-specific expression of the SAA proteins. Amyloid induction after viral expression of the SAA1.1 protein resulted in the deposition of amyloid fibrils in the CE/J mouse, whereas SAA2.2 expression had no effect. Similar expression of the SAA2.2 protein in C57BL/6 mice did not alter amyloid deposition. These data demonstrate that the failure of the CE/J mouse to deposit amyloid is due to the structural inability of the SAA2.2 to form amyloid fibrils. This mouse provides a unique system to test the amyloidogenic potential of altered SAA proteins and to determine the important structural features of the protein. (Lab Invest 2000, 80:1797-1806).

\begin{abstract}
S erum amyloid A proteins (SAA) are associated in $\int$ the serum with high-density lipoproteins (HDL). During inflammatory conditions, SAA levels can increase 1000-fold, reaching $1 \mathrm{mg} / \mathrm{ml}$ (Benditt and Ericksen, 1977; Benson and Kleiner, 1980; Hoffman and Benditt, 1982). Secondary amyloidosis is contingent upon the chronic induction of SAA proteins, which are the precursors to amyloid fibrils. In mice, widespread AA amyloid is deposited after injection of amyloid-inducing factors such as casein or amyloid enhancing factor (AEF) and silver nitrate (SN) (Axelrad et al, 1982; McAdam and Sipe, 1976). SAA proteins are acute-phase reactants that originate in the liver and are liberated into the plasma after cytokine stimulation (Sipe et al, 1982; Vogel and Sipe, 1982). In the mouse, the two acute-phase SAA proteins are SAA1.1 and SAA2.1; during inflammation-associated amyloid formation, only the SAA1.1 isoform is deposited into amyloid (Meek et al, 1986; Shiroo et al 1987). The CE/J
\end{abstract}

Received June 19, 2000.

This research was supported in part by the National Institute for Neurological Diseases and Stroke (NS32221) and the National Institute on Aging (AG12981). Additional funding was obtained through the Stroke Program of the Sanders-Brown Center on Aging. JTG was an Academic Year Fellow. Address reprint requests to: Dr. Mark S. Kindy, Department of Biochemistry, 800 Rose Street, Lexington, Kentucky 40536-0084. Fax: 606257 8990;E-mail:mskindy@pop.uky.edu mouse contains a single SAA gene, SAA2.2, which seems to be a composite of the SAA1.1 and SAA2.1 genes (de Beer et al, 1993). The amino terminus of the protein is identical with SAA2.1, whereas the carboxy terminus resembles both SAA1.1 and SAA2.1 proteins (Patel et al, 1996). Because the amyloidogenic capabilities of the SAA1.1 protein exist in the amino terminal region, the CE/J mouse lacks an acute-phase SAA isoform structurally identical with the SAA1.1 (de Beer et al, 1993). When CE/J mice are induced with AEF and $\mathrm{SN}$, they are totally resistant to amyloid formation (Sipe et al, 1993). In vitro experimental evidence indicates that the SAA2.2 protein does not form fibrils (nonamyloidogenic), whereas the SAA1.1 isoform is highly amyloidogenic (Kindy et al, 1998).

Recent studies have been designed to elucidate the mechanism of this resistance (Elliott-Bryant et al, 1996; Gonnerman et al, 1995, 1996; Liang et al, 1998). Results suggest that the CE/J mice, although they do not develop amyloidosis, have detectable AEF activity in the spleen (Gonnerman et al, 1996). Furthermore, the SAA2.2 protein in CE/J mice was not degraded by peritoneal macrophages and SAA2.2 bound to the macrophages with a higher affinity than SAA1.1 or SAA2.1 (Elliot-Bryant et al, 1996; Liang et al, 1998). Amyloid immunity in the CE/J mouse was examined by crossing the $\mathrm{CE} / \mathrm{J}$ mouse with the amyloidsusceptible CBA/J strain (Gonnerman et al, 1995). F2 
generation animals expressed either the SAA1.1 and SAA2.1 isoforms, or the SAA2.2 isoform concomitantly with the SAA1.1 and SAA2.1 proteins. The correlation of amyloid-resistance was obligatory for the expression of the SAA2.2 isoform. Additionally, Mus musculus czech were shown to be amyloidresistant and this resistance correlated with the expression of the novel SAA protein found in the $M$. musculus czech strain (Cathcart et al, 1996). These studies intimate that the SAA2.2 isoform (and similar SAA protein configurations) could confer protection against amyloidogenesis.

AA amyloidosis is the consequence of a two-step sequence involving a pre-amyloid program and an amyloid program (Sipe et al, 1978). The first step requires the generation of a precursor protein in appreciable quantities to initiate deposition. The pre-amyloid phase, which can persist for days to years without the appearance of amyloid deposits, is totally dependent upon the type of stimuli and the level of SAA expression. The liberation of cytokines (interleukin-1, interleukin-6, and tumor necrosis factor) via macrophage activation through chronic inflammation or recurrent acute inflammation results in hepatocyte production of acute phase SAA (Baumann and Gauldie, 1990; Grunfeld et al, 1992). The amyloid phase results from the creation of a nidus or fibrillar network that allows for the deposition of amyloidogenic proteins (Kisilevsky, 1996). This step is contingent upon the structural and metabolic characteristics of the SAA molecule and the conditional requirement of ancillary factors such as serum amyloid $\mathrm{P}$ component, apolipoprotein E (apoE), and proteoglycans (Botto et al, 1997; Kindy and Rader, 1998; Kisilevsky et al, 1995). The generation of this nidus permits the accelerated and augmented deposition of AA fibrils (Come et al, 1996).

In this study, we used adenoviral vectors that expressed both the mouse SAA1.1 and SAA2.2 proteins in vivo to determine the amyloidogenic potential of the $\mathrm{CE} / \mathrm{J}$ mouse. As described previously, adenoviral expression resulted in the synthesis of SAA protein and its incorporation onto HDL particles (Kindy et al, 1998). Additionally, recent in vitro studies showed that the CE/J protein was not capable of inhibiting amyloid formation (Kluve-Beckerman et al, 1999). Transient high-level hepatic expression of SAA2.2 in CE/J mice did not induce amyloid deposition, whereas expression of the mouse SAA1.1 protein in CE/J mice resulted in typical amyloid fibril formation. Conversely, introduction of the SAA2.2 protein into C57BL/6 mice did not alter the amyloidogenic capacity of these mice. These investigations indicate that the CE/J mouse is capable of amyloid formation if amyloidogenic isoforms of SAA are expressed. These studies further demonstrate the potential utility of adenoviral vectors in the expression of proteins for functional analysis.

\section{Results}

\section{Fibrillogenic Analysis of SAA Proteins}

To demonstrate the fibrillogenic potential of the SAA proteins, we purified both mouse SAA1.1 and SAA2.2 from CV-1 monkey kidney cells and subjected them to in vitro fibrillogenesis (Fig. 1). With incubation at $37^{\circ} \mathrm{C}$, SAA1.1 (Fig. 1B) formed fibrils reminiscent of AA fibrils (Fig. 1A). In contrast, SAA2.2 was inefficient at forming fibrils when incubated under the same conditions (Fig. 1C). ApoA-I was used as a control hydrophobic protein that does not form fibrils (Fig. 1D). Some aggregation of protein was seen in the apoA-I samples, but fibrils were never seen. As shown in Figure 2, when $A A$ fibrils were incubated in the presence of SAA1.1, there was an increase in thioflavin $T$ fluorescence, which extended in a linear fashion. As shown in Figure 1, when SAA2.2 was incubated in the presence of AA fibrils, no fluorescence was detected, indicating a lack of fibrillogenesis. Addition of increasing concentrations of SAA2.2 to the incubation mixture containing SAA1.1 and AA fibrils showed no change in fibril formation. Addition of 0.5 or $1 \mathrm{mg} / \mathrm{ml}$ of SAA2.2 did not alter the ability of SAA1.1 to form fibrils in vitro, indicating that SAA2.2 does not inhibit amyloid fibril extension.

\section{SAA Gene Transfer and Liver Expression}

Recombinant adenoviruses (previously described) were injected into mice at $2 \times 10^{11}$ particles per mouse (Webb et al, 1997). Figure 3 shows the expression levels of $S A A$ in $C E / J$ mice injected with the null, $S A A 2.2$, and $S A A 1.1$ viruses. Saline-injected and null virus-injected $C E / J$ mice showed very little $S A A$ expression after 72 hours (null virus-injected mice had a slight elevation of SAA mRNA compared with controls). Earlier time points showed even less SAA mRNA expression (data not shown). SAA2.2-injected and $S A A 1.1$-injected mice showed significant increases in $S A A$ expression from the adenovirus genome when compared with the control and null-virus injected animals. Oligonucleotide probes were used to demonstrate the specific changes in the different adenovirally expressed SAA isoforms (data not shown). All AEF/SN-injected animals expressed high levels of $S A A$ mRNA that were indistinguishable from each other.

To verify that the increase in mRNA seen in Figure 3 translated into protein expression, plasma from control and adenovirus-injected animals was isolated and subjected to isoelectric focusing and Western blot analysis (Fig. 4). Control CE/J mice did not have detectable levels of SAA protein in their plasma, whereas lipopolysaccharide (LPS) -injected mice had an increase in a single SAA isoform that migrated with a pl of 6.15. CE/J animals injected with null adenovirus showed a minor change in SAA. This change in SAA was masked by injection of LPS, which dramatically increased in SAA2.2 expression. Injection of CE/J mice with the SAA2.2 virus resulted in a modest increase in SAA2.2 protein, to a level approximately 3 to 5 fold more than the null virus-injected animals, indicating a contribution from the adenovirusexpressed SAA2.2 protein. When the SAA2.2 virus and LPS injections were combined, there was a dra- 

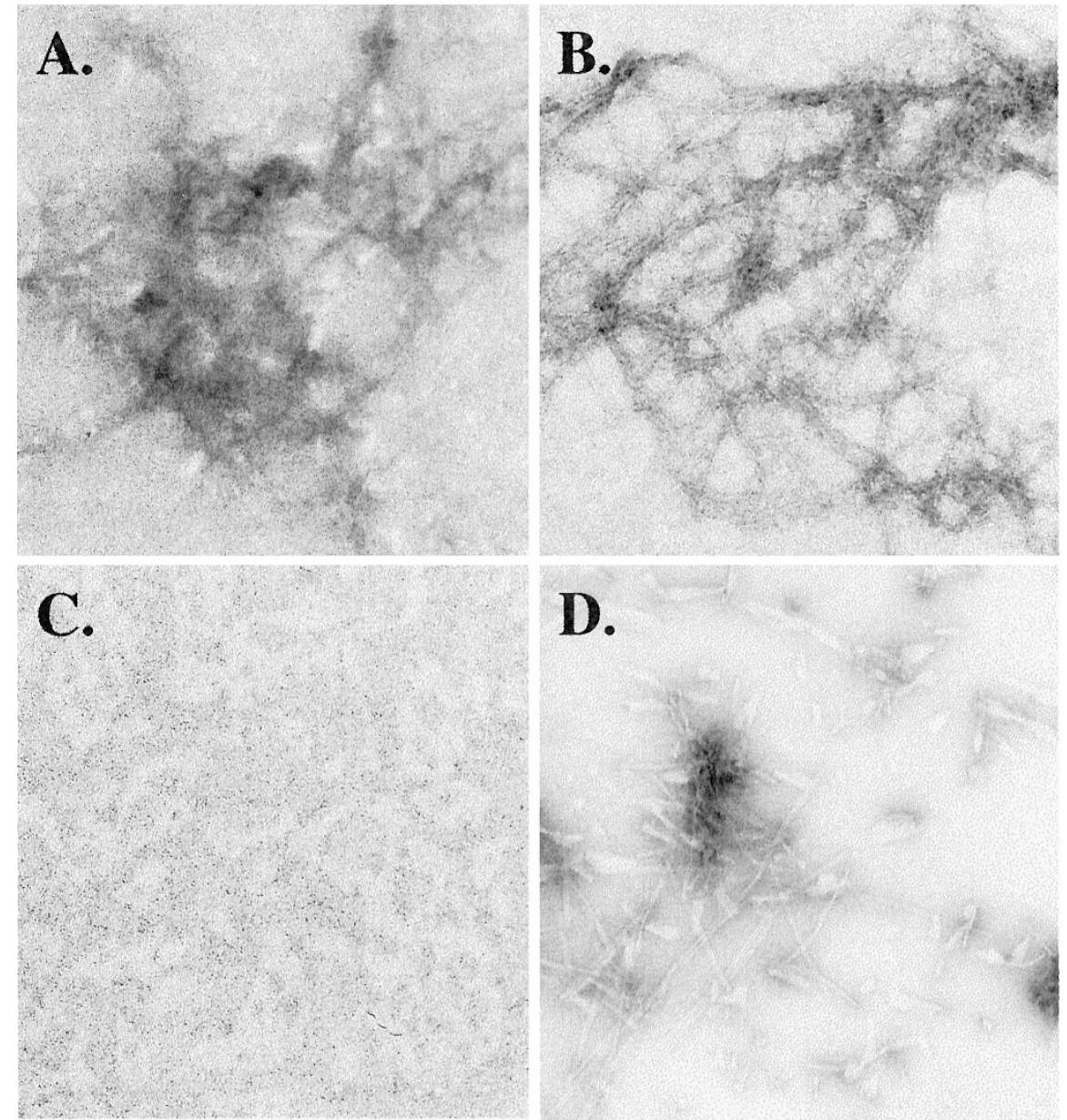

\section{Figure 1}

Electron micrographs of in vitro fibrillogenic potential of serum amyloid A (SAA) isoforms. SAA proteins were expressed in CV-1 cells using adenoviral vectors, purified, and subjected to fibril formation at $37^{\circ} \mathrm{C}$ in $10 \mathrm{~mm}$ Tris, $\mathrm{pH}$ 7.4. A, amyloid A (AA) fibrils isolated from amyloidogenic mouse spleens; $B$, fibrillization of the SAA1.1 protein was apparent after 72 hours of incubation; $C$, SAA2.2 showed no fibrillar extensions; $D$, apoA-I protein demonstrated the lack of fibrils. Original magnification, $\times 20,000$.

matic increase in SAA protein expression. SAA1.1 viral expression demonstrated the presence of the SAA1.1 protein, which is not normally found in CE/J mice. Injection of the SAA1.1 virus along with LPS showed expression of SAA2.2 at acute-phase levels and SAA1.1 at virally expressed levels. Acute-phase C57BL/6 mouse plasma was used as a control for the SAA2.1 and SAA1.1 proteins.

\section{Amyloid Formation in the CE/J Mouse}

To test the ability of the SAA2.2 isoform to inhibit amyloid formation in the CE/J mouse, we injected the $\mathrm{CE} / \mathrm{J}$ mice with the different adenoviral SAA isoforms in the presence of $A E F / S N$ and examined splenic tissue for amyloid deposition (Fig. 5). As shown previously, control and AEF/SN-injected CE/J mice did not develop AA amyloid (Fig. 5A and B, respectively) compared with C57BL/6 mice, which when subjected to AEF/SN injection, develop extensive splenic amyloid (Fig. 5H). When CE/J mice were injected with either the null virus or the SAA2.2 virus, no amyloid was detected in the spleen (Fig. 5C and D, respectively). However, when inoculated with the virus expressing the amyloidogenic SAA1.1 protein, mice rapidly developed amyloid similar to that seen in the C57BL/6 mice (Fig. 5E compared with Fig. 5H). When these spleens were subject to immunocytochemical analysis with rabbit-anti-mouse SAA antibodies, the splenic amyloid was identified as AA amyloid (Fig. 5F).

Quantification of amyloid in the C57BL/6 and CE/J mice was performed using image analysis to assess the area and intensity of the amyloid present in the splenic tissue (Fig. 6). Figure 6A shows the quantification of the amyloid seen in Figure 5. As in Figure 5, control and AEF/SN-injected CE/J mice have no amyloid. Furthermore, AEF/SN plus null virus-injected and AEF/SN plus SAA2.2-injected animals do not have detectable amyloid by Congo red staining (Fig. 5, C and $D$, respectively) or by immunocytochemical analysis (data not shown). In contrast, CE/J mice injected with the SAA1.1 virus and AEF/SN showed a dramatic presence of amyloid in the spleen with more than $25 \%$ 


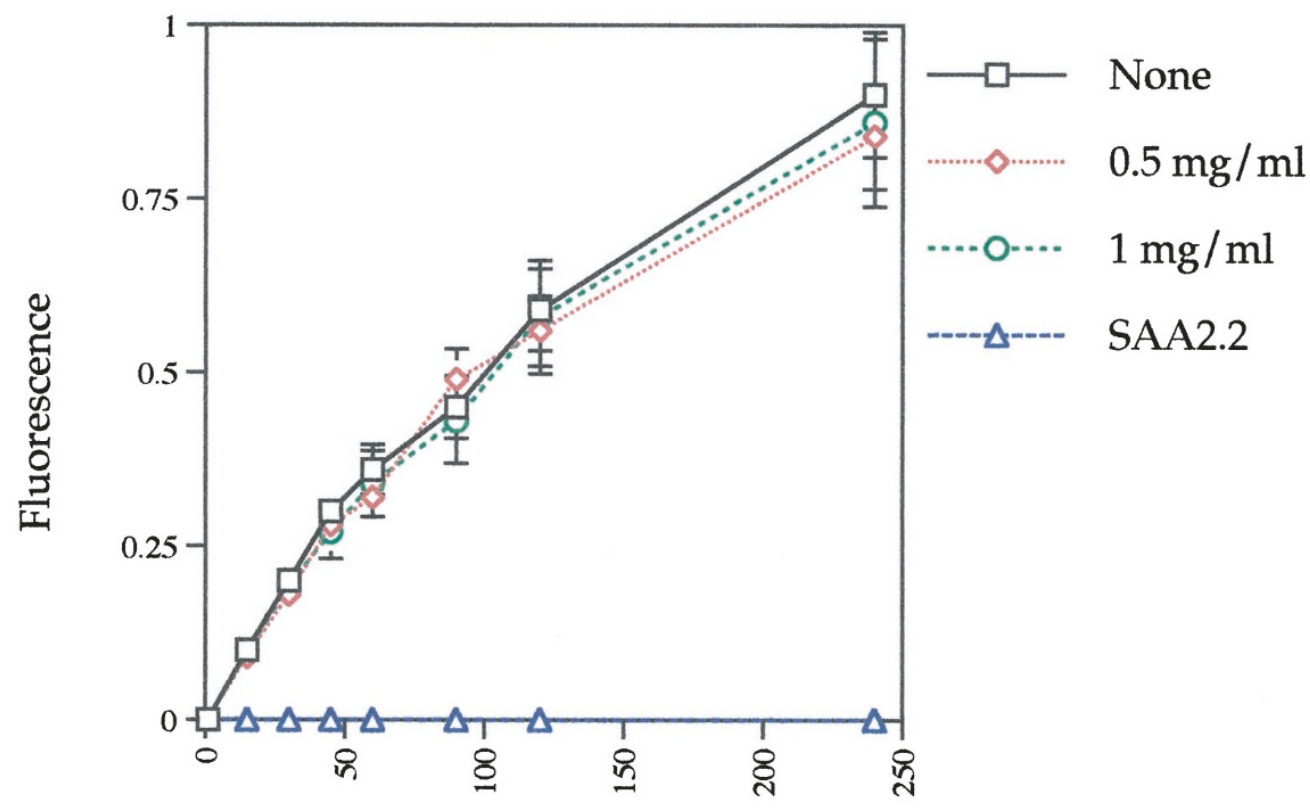

\section{Time in minutes}

\section{Figure 2.}

SAA1.1 fibril formation in the absence and presence of SAA2.2 in vitro. Measurement of changes in fluorescence over time with SAA1.1 protein. Samples were composed of $50 \mathrm{ng} / \mathrm{ml}$ of AA fibrils, $1 \mathrm{mg} / \mathrm{ml}$ of SAA1.1 in $10 \mathrm{~mm}$ Tris, pH 7.4 plus no additions ( $\square$ ), SAA2.2 at $0.5 \mathrm{mg} / \mathrm{ml}(\diamond)$, SAA2.2 at $1 \mathrm{mg} / \mathrm{ml}$ (O), or SAA2.2 alone at $1 \mathrm{mg} / \mathrm{ml}(\triangle)$. Data represent results from four separate assays performed in triplicate. Numbers are mean \pm SEM.

\section{$\mathrm{CE} / \mathrm{J}$}

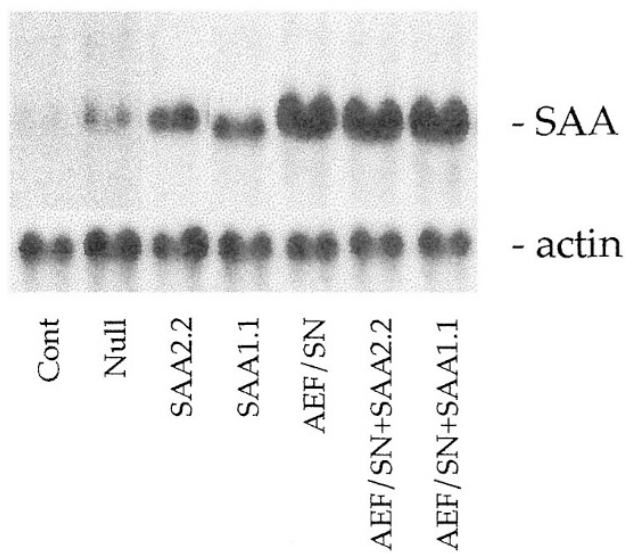

\section{C57BL/ 6}

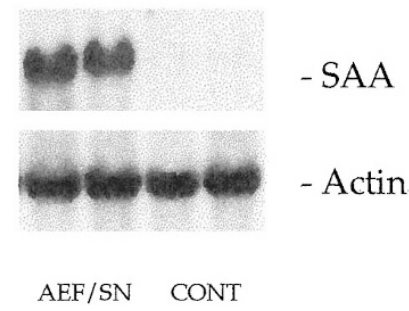

$\mathrm{AEF} / \mathrm{SN} \quad \mathrm{CONT}$

Figure 3.

Expression of SAA mRNA in CE/J and C57BL/6 mice using adenovirus top direct liver-specific expression. Mice were either not injected or were injected with different SAA adenoviruses to allow for specific expression of the SAA mRNA. Adenovirus was injected at $2 \times 10^{11}$ particles per mouse. Left, Total RNA was prepared from control and infected livers of mice 72 hours after tail vein injection of adenoviruses. Lane 1, control CE/J; lane 2, CE/J mouse injected with null virus; lane 3, CE/J mouse injected with SAA2.2 virus; lane 4, CE/J mouse injected with SAA1.1 virus; lane 5, CE/J mouse injected with amyloid enhancing factor (AEF) and silver nitrate (SN) (AEF/SN); lane 6, CE/J mouse injected with SAA2.2 virus followed by injection of AEF/SN; lane 7, CE/J mouse injected with SAA1.1 virus followed by injection of AEF/SN. Right, Total RNA isolated from control and AEF/SN-treated C57BL/6 mice. Lanes 1 and 2, RNA from AEF/SN-treated animals; lanes 3 and 4, RNA from control mice. Twenty micrograms of total RNA was subjected to electrophoresis per lane and blots were hybridized with a radiolabeled SAA1.1 cDNA that was randomly primed. Alternatively, blots were probed with a rat $\beta$-actin cDNA (lower pane).

of the tissue containing amyloid fibrils (Fig. 6A). This difference was significant $(p>0.001)$ and the amount of amyloid was comparable to AEF/SN-treated C57BL/6 mice (Fig. 6B). Furthermore, C57BL/6 mice injected with null virus, SAA2.2 virus, and AEF/SN showed no difference in amyloid deposition compared with $\mathrm{AEF} / \mathrm{SN}$ injection alone (Fig. 6B). C57BL/6 mice injected with both SAA1.1 virus and AEF/SN demon- 


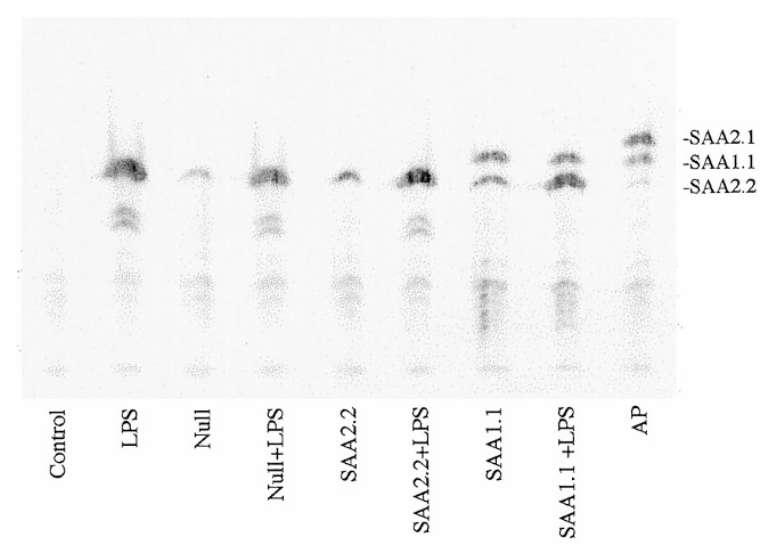

Figure 4.

SDS-PAGE, isoelectric focusing and Western blot analysis of plasma samples from adenoviral injected animals. Mice were prepared as indicated and plasma was isolated and subjected to SDS-PAGE, isoelectric focusing and Western blot analysis. For adenovirus-injected mice, animals were injected with virus and plasma was collected after 72 hours. Alternatively, animals were injected with adenovirus and then injected with lipopolysaccharide (LPS) after 48 hours. Plasma was collected 24 hours later. LPS-treated animals were sacrificed after 24 hours (LPS: CE/J mouse; AP: acute-phase C57BL/6 mouse). Blots were subjected to immunoblot analysis using rabbit-anti-mouse acutephase SAA antibodies.

strated a slight increase in amyloid deposition, possibly due to an increase in the presence of precursor protein.

\section{Discussion}

In this study, we used adenoviral vectors that express various isoforms of the SAA proteins to examine the structural features that may be involved in the fibrillogenesis of AA amyloid. Expression of the amyloidogenic SAA1.1 isoform in "amyloid-resistant" CE/J mice resulted in the deposition of $A A$ amyloid consistent with the hypothesis that the SAA2.2 protein lacks the necessary structural features to form amyloid. Expression of the nonamyloidogenic SAA2.2 isoform in "amyloid-competent" C57BL/6 mice did not suppress or inhibit the pathogenesis of amyloidosis.

Previous studies demonstrated that the CE/J mouse is completely resistant to amyloid formation and our data suggests that this is due to the altered structural features of the SAA2.2 isoform. To determine the nature of this resistance, we developed adenovirus vectors that expressed different SAA isoforms (Kindy et al, 1998; Webb et al, 1997). We used "secondgeneration" adenoviruses that have reduced immunologic effects because of a mutation in the E2a gene, minimizing the potential interference from viralmediated responses (Engelhardt et al, 1994). Synthesis of the exogenous proteins from the adenoviruses can be maintained for up to 3 months without a significant decrease in protein expression (Tsukamoto et al, 1997). During inflammation, the HDL particle is dramatically remodeled, with SAA becoming the major protein entity (Coetzee et al, 1986). Changes in the size of the HDL particle and a decrease in apoA-I concentration may be important in HDL function and amyloid deposition (Pepys and Baltz, 1983). Adenovi- ral expression of the acute-phase SAA proteins resulted in high levels of SAA synthesis, which caused a modest increase in the size of the HDL particle (Tsukamoto et al, 1997). However, this level of SAA did not alter apoA-I protein concentrations nor did it affect cholesterol levels in non-acute-phase HDL. Therefore, it is unlikely that adenovirus-mediated effects could alter amyloid deposition.

Suppression of amyloid deposition in mice has been demonstrated in a number of animal models, suggesting a potential strategy for slowing the process of amyloidogenesis (Chiba et al, 1999; Telling et al, 1996). Expression of wild-type prion protein $\left(\operatorname{PrP}^{\mathrm{C}}\right)$ delayed the onset of amyloid plaques and neurologic changes in transgenic mice expressing the mutated form of the PrP protein (Telling et al, 1996). Adenoviralmediated transfer of the type B apoA-II protein inhibited the pathogenesis of amyloid in type $\mathrm{C}$ mice, which have a high incidence of the senile amyloidosis apoA-Il gene (Chiba et al, 1999). Furthermore, the inbred crossing of the CE/J "amyloid resistant" strain to an "amyloid prone" strain suppressed the development of AA amyloid (Gonnerman et al, 1995). The mechanism of suppression is not known. However, it is possible that the "nonamyloidogenic" protein will interact with the "amyloidogenic" protein and inhibit fibrillogenesis by blocking an active site or disrupting fibril stability (Gonnerman et al, 1995). A concern with this hypothesis is that in $\mathrm{AA}$ amyloidogenic mice both the amyloidogenic SAA1.1 and nonamyloidogenic SAA2.1 are expressed at equivalent levels, yet these mice still develop amyloid quite easily. It is more likely that the nonamyloidogenic proteins interfere with amyloid formation through a competitive mechanism, both in vitro by a concentration effect and in vivo by a concentration and possibly a heparan sulfate interaction effect (Ancsin and Kisilevsky, 1999). It would be interesting to determine the amyloidogenic capacity of a mouse devoid of all SAA proteins. If the nonamyloidogenic SAA interferes with fibrillogenesis, viral expression of the amyloidogenic SAA in the SAAdeficient animals should result in more rapid and extensive amyloid deposits.

$\mathrm{CE} / \mathrm{J}$ mice are valuable as a biological tool because of their resistance to amyloid induction. The SAA2.2 isotype differs from the amyloidogenic SAA1.1 isotype by only six amino acids (de Beer et al, 1993) (Fig. 7). The aspartic acid at position 101 is probably not important because this is the same substitution that exists in the SJL/J mouse SAA isoform that can be deposited as amyloid (Rokita et al, 1989). Thus, the amino acid substitution that confers resistance to the SAA2.2 isotype resides within the 5 remaining substitutions, and the precise definition of the molecular motif that confers amyloidogenicity can potentially be resolved by site-directed mutagenesis. The amino acid substitutions at positions 6,60 , and 63 are conservative. The amino acid substitution at position 7 , where the glycine of the amyloidogenic SAA1.1 is replaced with a histidine, may be more significant. This substitution could result in significant secondary structural variations. The unique amino acid substitu- 


\section{A. Control CE/J}

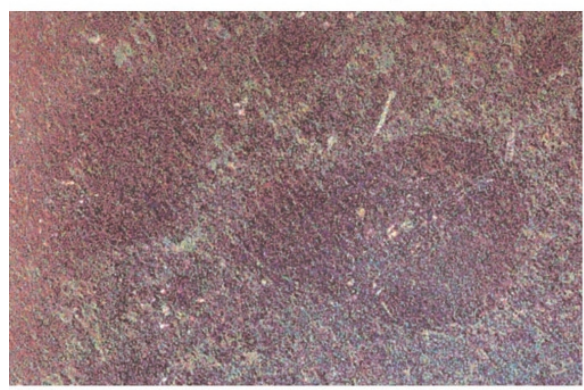

\section{Null AEF CE/J}

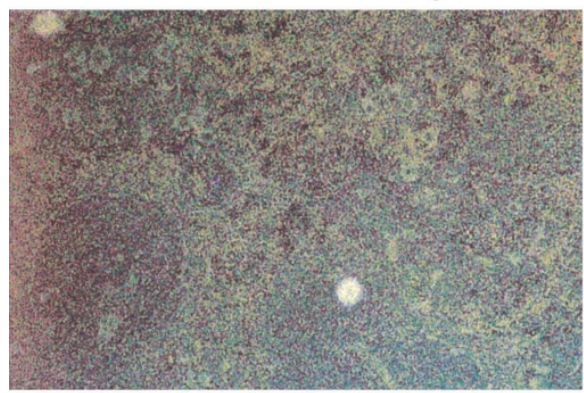

\section{E. SAA1.1 AEF CE/J}

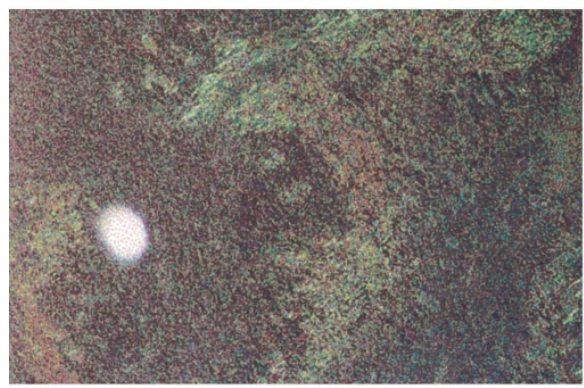

\section{G. Control C57BL/6}

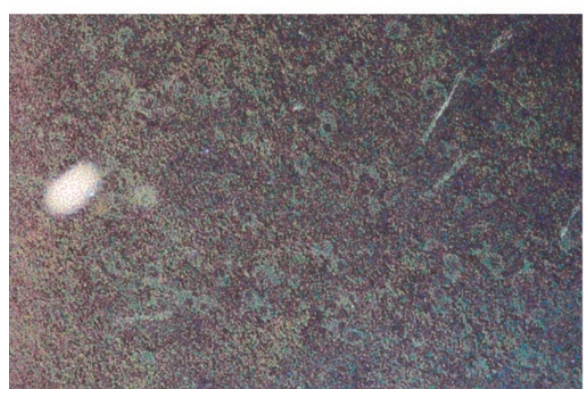

B. AEF CE/J

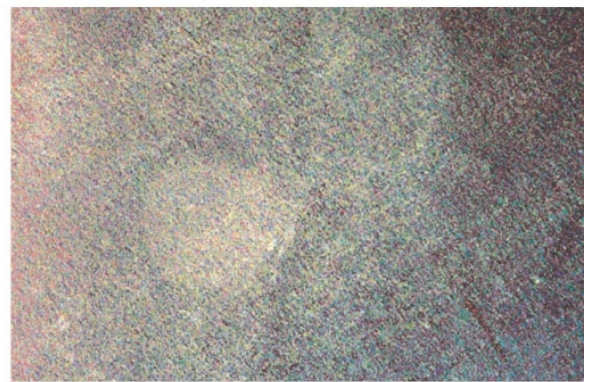

D. SAA2.2 AEF CE/J

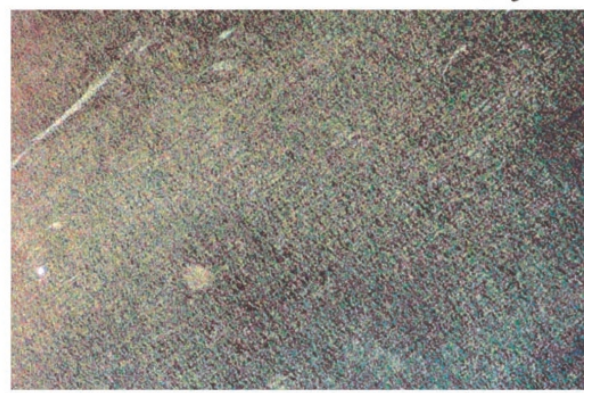

\section{F. SAA1.1 AEF CE/J}

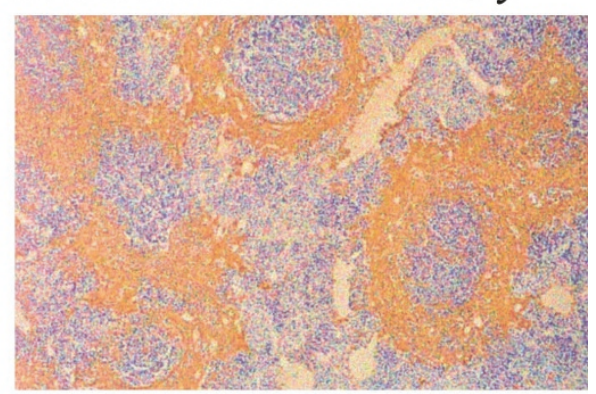

H. AEF C57BL/6

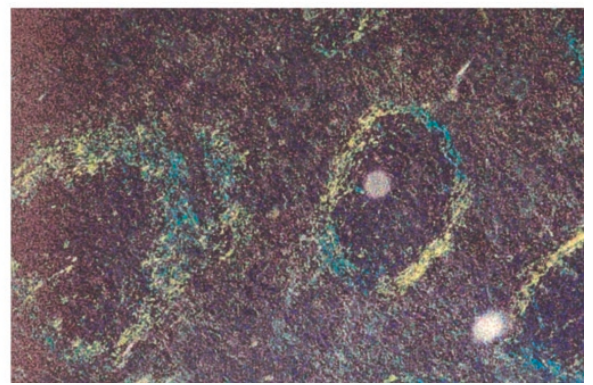

\section{Figure 5}

Amyloid formation in the CE/J mouse after expression of mouse SAA isoforms. CE/J mice were not injected $(A)$, injected with AEF/SN $(B)$, or injected with adenoviruses expressing: null virus $(C)$; SAA2.2 virus $(D)$; or SAA1.1 virus $(E)$. C57BL/6 mice were either not injected $(G)$ or injected with AEF/SN $(H)$ plus AEF/SN. Mice were either injected with AEF/SN and killed after 5 days or were injected with adenoviruses, injected with AEF/SN after 3 days, and killed after an additional 5 days. The spleens were removed for amyloid determination. Amyloid deposition was confirmed by Congo red staining. Spleens from CE/J mice injected with SAA1.1 and AEF/SN were subjected to immunocytochemical analysis using rabbit-anti-mouse acute-phase SAA antibodies $(F)$. AEF indicates AEF/SN.

tion at position 11, where the leucine of the SAA2.2 protein displaces a glutamine present in the SAA1.1 and SAA2.1 proteins, is reminiscent of the glutamic acid to glutamine substitution of the $A \beta$ fibril peptide, where the presence of the glutamine correlates with a greater stability of fibrils. However, because nonamyloidogenic SAA2.1 is identical with the amyloidogenic SAA1.1 in this position, the importance of this substitution is questionable. Peptide studies have narrowed the amyloidogenic region to positions 6 and 7 of the 


\section{A. $\mathrm{CE} / \mathrm{J}$}

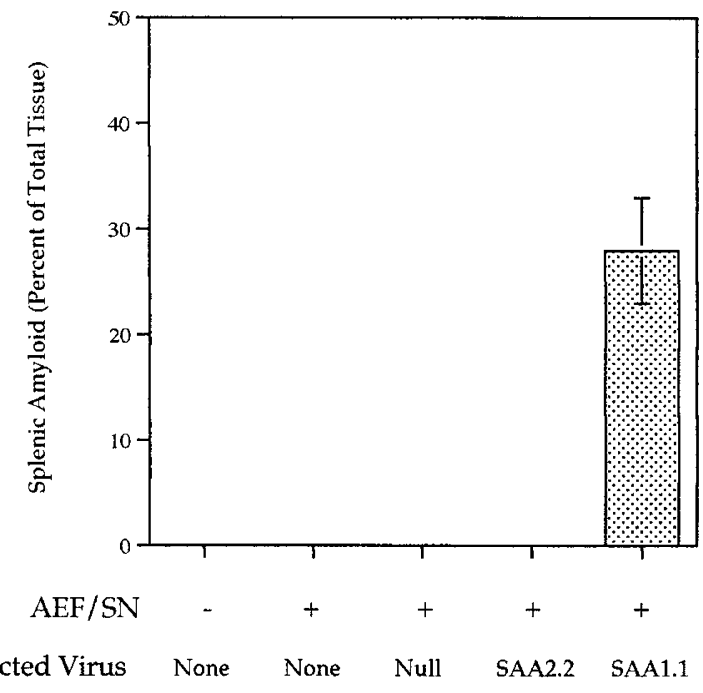

B. $\mathrm{C} 57 \mathrm{BL} / 6$

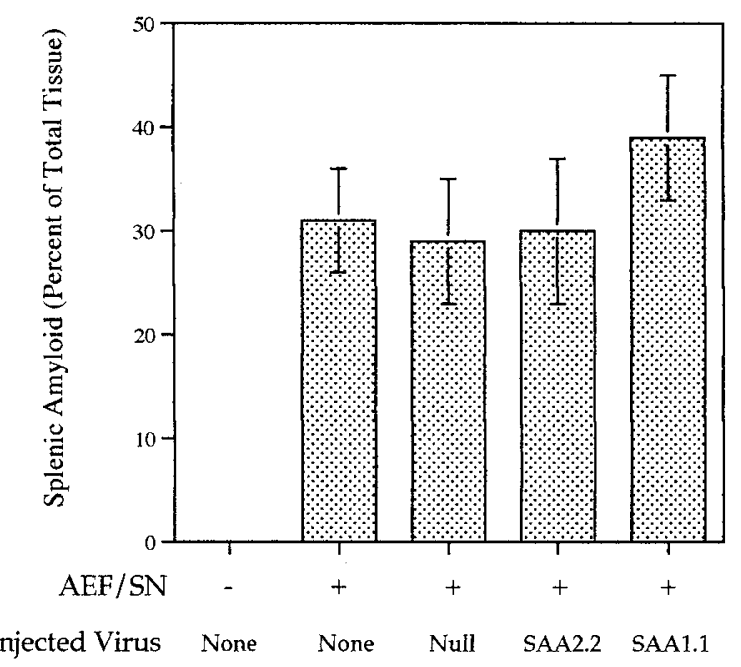

Figure 6.

Quantification of amyloid deposition in CE/J and C57BL/6 mice. Mice were injected as described in Figure 3 and subjected to quantification under polarized filters by apple-green birefringence in sections stained with Congo red. The amount of amyloid in the tissue was expressed as a percent of the tissue that contained amyloid based on image analysis. AEF/SN-injected mice: AEF/SN. CE/J $(A)$ or C57BL/6 (B) mice were injected with adenoviruses and examined for amyloid deposition. Ten mice were injected per group. Data is presented as mean \pm SEM.

SAA1.1 G F F S F I G E A F $\mathbf{Q}$ G A G D M W R A Y T D M K E A G W K D G D K Y F H A R G N SAA2.1 G F F S F V H E A F Q G A G D M W R A Y T D M K E A N W K N S D K Y F H A R G N SAA2.2 G F F S F VH E A F L G A G D M W R A Y T D M K E A G W K D G D K Y F H A R G N 10 20

SAA1.1 Y D A A Q R G P G G V A A E K I S D A R E S F Q E F F G R G H E D T M A D Q E SAA2.1 Y D A A Q R G P G G V W A A E K I S D G R E AF Q E F F G R G H E D T I A D Q E SAA2.2 Y D A A Q R G P G G V W A A E K I S D

\author{
SAA1.1 A N R H G R S G K D P N Y Y R P P G L P A K Y \\ SAA2.1 A N R H G R S G K D P N Y Y R P P G L P D K Y \\ SAA2.2 A N R H G R S G K D P N Y Y R P P G L P D K Y \\ 90
}

Figure 7.

Amino acid sequence of mouse SAA proteins. Mouse SAA1.1, SAA2.1, and SAA2.2 protein sequences. The proteins indicated in the figure are the mature proteins and the bold letters denote the differences between the distinct SAA proteins. The SAA2.2 protein is the SAA found in the CE/J mouse.

SAA proteins, and purified human proteins suggest that this is the region of importance (Patel et al, 1996). Therefore, future studies will focus on positions 6 and 7 of the SAA molecule and will enable us to examine these alterations in vivo.

In the present study, we showed that expression of the amyloidogenic SAA1.1 isoform initiated amyloid formation in the putative "amyloid resistant" $\mathrm{CE} / \mathrm{J}$ mouse. These results suggest that the structural fea- tures of the SAA1.1 protein are essential for amyloid formation and the SAA2.2 isoform is devoid of this property. In vitro analysis has demonstrated that the amino terminus may be important for fibrillogenesis of the SAA proteins. However, these studies need to be extended into an in vivo setting to determine the actual consequences of the altered proteins (Patel et al, 1996). The development of adenoviral vectors or transgenic mice that express SAA proteins with mu- 
tations in the fibrillogenic region of the molecule will help delineate the requirements for the pathogenesis of AA amyloid. Additionally, these studies are essential to our understanding the fundamental principals of nucleation and abnormal protein assembly in amyloid diseases.

\section{Materials and Methods}

\section{Reagents}

All reagents used in this study were of the highest quality and were obtained from Sigma Chemical Company, St. Louis, Missouri, unless otherwise stated. SAA antibodies were prepared from acute-phase SAA protein as described previously (Kindy and de Beer, 1999).

\section{Animals}

C57BL/6 and CE/J mice were obtained from Jackson Laboratories, Bar Harbor, Maine. An acute-phase was elicited in adult mice by intraperitoneal injection of 25 $\mu \mathrm{g}$ of LPS (Escherichia coli: 0111B4, Difco Laboratories, Detroit, Michigan), or SN ( $0.5 \mathrm{ml}$ of a $2 \%$ solution). Amyloid was induced in mice by subcutaneous injection of azocasein $(0.5 \mathrm{ml})$ for 21 days or intravenous injection of $A E F(0.1 \mathrm{ml}$ of a $1 \mathrm{mg} / \mathrm{ml}$ solution $)$ and $\mathrm{SN}$ ( $0.5 \mathrm{ml}$ of a $2 \%$ solution) for 5 days.

\section{RNA Analysis}

Livers from animals were frozen in liquid nitrogen after isolation. RNA was extracted as described previously (Kindy et al, 1995). Northern blots were probed with cDNA directed against mouse SAA1.1 mRNA. DNA probes were labeled using the random primer method as described previously (Feinberg and Vogelstein, 1984).

\section{Preparation of $H D L$}

HDL was isolated from plasma essentially as described previously (de Beer et al, 1995). Yields from equal volumes of $\mathrm{C} 57 \mathrm{BL} / 6$ and $\mathrm{CE} / \mathrm{J}$ mice plasma were calculated. HDL was isolated from normal animals and from animals subjected to inflammatory response. Inflammation was induced in mice by subcutaneous injection of $0.5 \mathrm{ml}$ of a $2 \%(\mathrm{w} / \mathrm{v})$ solution of aqueous SN. For collection of normal HDL, untreated animals were anesthetized with Metofane and exsanguinated via heart puncture into syringes coated with 7\% EDTA. For acute-phase HDL, animals were prepared as described above, and after 24 hours were anesthetized with Metofane and exsanguinated via heart puncture into syringes coated with $7 \%$ EDTA. HDL was purified from plasma by ultracentrifugation as previously described. Briefly, plasma density was adjusted to $1.09 \mathrm{~g} / \mathrm{ml}$ with solid potassium bromide and then centrifuged for 5.3 hours at $242,000 \times \mathrm{g}$ in a Vti90 rotor (Beckman Instruments, Palo Alto, California) at $10^{\circ} \mathrm{C}$. Very low density lipoprotein and low density lipoprotein samples were collected, and the infranatants containing the HDL were collected and adjusted to $1.21 \mathrm{~g} / \mathrm{ml}$ potassium bromide and centrifuged for 9.4 hours at $242,000 \times \mathrm{g}$ in a Vti90 rotor. HDL was collected from the top of the tube and dialyzed extensively against $150 \mathrm{mmol} / \mathrm{L}$ of $\mathrm{NaCl}$, $0.1 \%$ EDTA, pH 7.4 .

\section{Adenoviral Generation}

The production of replication-defective adenoviral vectors expressing mouse SAA proteins has been described using second generation adenoviral vectors (Webb et al, 1997). Briefly, recombinant adenoviruses were expanded in 293 human embryonic kidney cells. Virus was used to infect 293 cells and viral particles were isolated from the cells after 72 hours of infection and purified by density gradient cesium chloride centrifugation. Virus particles were centrifuged through a two-step gradient of cesium chloride $(1.45 \mathrm{~g} / \mathrm{ml}$ and $1.20 \mathrm{~g} / \mathrm{ml}$ ) for 2 hours and 14 hours, respectively. The virus particles were collected and chromatographed on a $10 \mathrm{ml}$ Econo-Pac DG column as described by the manufacturer (Bio-rad, Hercules, California). The number of particles was determined by optical density.

\section{Purification of SAA Proteins}

Mouse SAA1.1 and SAA2.2 proteins were produced in vitro by infection of CV-1 monkey kidney cells with adenoviral vectors at a dose of $1 \times 10^{10}$ particles per $1 \times 10^{6}$ cells. HDL was isolated as described above and subjected to delipidation (Kindy et al, 1998). SAA proteins were purified by Sepharose CL-6B chromatography in $4 \mathrm{~mol} / \mathrm{L}$ of guanidine, $0.05 \mathrm{~mol} / \mathrm{L}$ of Tris$\mathrm{HCl}, \mathrm{pH}$ 8.2, followed by chromatofocusing over a range of $\mathrm{pH} 8$ to $\mathrm{pH} 5$ in $6 \mathrm{~mol} / \mathrm{L}$ of urea (Yamada et al, 1994). Samples were dialyzed against water.

\section{In Vitro Fibril Formation}

Each purified protein was dissolved in $10 \mathrm{~mm}$ Tris- $\mathrm{HCl}$, $\mathrm{pH} 7.4$ at a concentration of $1 \mathrm{mg} / \mathrm{ml}$ and incubated for 72 hours at room temperature (Chiba et al, 1999; Westermark et al, 1992). Samples were dried on glass slides, stained with Congo red and examined under polarized light for fibril formation. Samples were diluted 1:5 or 1:10 with distilled water, placed on Formvar grids, stained with $1 \%(\mathrm{w} / \mathrm{v})$ uranyl acetate, and examined by electron microscopy. For co-incubation studies, amyloid fibril formation was determined by fluorometric assay using thioflavin T (Naiki et al, 1989). Samples were prepared in $10 \mathrm{~mm}$ Tris- $\mathrm{HCl}, \mathrm{pH} 7.4$ at $1 \mathrm{mg} / \mathrm{ml}$ and incubated at $37^{\circ} \mathrm{C}$ for up to 4 hours. The samples were assayed in a spectrofluorophotometer, with an excitation wavelength of $450 \mathrm{nM}$ and an emission wavelength of $482 \mathrm{~nm}$. The reaction included 250 nM thioflavin T.

\section{Electrofocusing and Immunochemical Analysis}

Aliquots of mouse serum $(7 \mu \mathrm{l})$ were subjected to electrofocusing as previously described (de Beer et al, 1993), using an ampholine gradient consisting of $20 \%$ 
(v/v) ampholines, $\mathrm{pH} 3$ to 10; 40\% (v/v) ampholines, $\mathrm{pH} 4$ to 6.5 ; and $40 \%$ (v/v) ampholines, $\mathrm{pH} 7$ to 9 (Amersham Pharmacia). Samples on electrofocusing gels were subjected to immunochemical analysis as described previously (de Beer et al, 1993).

\section{Protein Studies}

Plasma and HDL samples from mice were subjected to SDS-PAGE and Western blot analysis (Strachan et al, 1988). Samples were prepared as described previously for isoelectric focusing (de Beer et al, 1995). SAA on Western blots was measured using a rabbit-antimouse SAA antibody (prepared against purified mouse SAA proteins, and reacts with AA amyloid) at a 1:1000 dilution and chemiluminescence (Kindy and de Beer, 1999). Apolipoproteins were quantified after electrophoresis on $5 \%$ to $20 \%$ reducing acrylamide SDS gels and electroblotting onto nitrocellulose. Densitometric scanning of films was performed using standard curves generated from purified SAA. Amyloid fibrils were isolated from the amyloidogenic mice as described previously (Pras et al, 1968).

\section{Amyloid Induction}

For control studies, mice were injected with $100 \mu \mathrm{g}$ of AEF into the lateral tail vein followed by subcutaneous injection of $0.5 \mathrm{ml}$ of SN. AEF was prepared as described previously (Axelrad et al, 1982). To test for amyloid deposition in mice, animals were injected with adenoviral vectors 3 days before injection of AEF and SN (as described above). Adenoviral vectors were injected at $2 \times 10^{11}$ particles per $25 \mathrm{gm}$ of mouse weight. Animals were killed at the end of the experiment. Tissues were excised, placed in formalin, and embedded in paraffin. Eight-micron-thick sections were cut and subjected to Congo red staining or immunocytochemical analysis with anti-mouse SAA antibodies. Congo red staining was performed as described previously (Puchtler and Sweat, 1965). For immunocytochemical analysis, sections were blocked with goat serum and incubated with a 1:1000 dilution of primary antibody overnight at $4^{\circ} \mathrm{C}$ (Kindy et al, 1995). The sections were washed and incubated with a goat-anti-rabbit secondary antibody linked to alkaline phosphatase. After washing, the sections were placed in diaminobenzidine $\mathrm{HCl}$ and counterstained with hematoxylin. Quantification of amyloid was achieved by Congo red staining and image analysis (Kindy and de Beer, 1999). Briefly, amyloid was quantified by digitizing the immunocytochemical or Congo red image for color (intensity and area) under low power (magnification, $\times 20$ ) and compared with standard amyloid-containing sections $(0 \%, 10 \%, 20 \%$, $30 \%, 40 \%$, and $50 \%$ of the tissue containing amyloid).

\section{Statistical Analysis}

All data was presented as the mean \pm standard error. Amyloid determinations were analyzed by ANOVA with Fisher's protected least significant difference. A probability value of less than 0.05 was regarded as indicative of a significant difference.

\section{Acknowledgements}

We thank John Cranfill, B.S., and Richard Parks, B.S., for excellent technical assistance; Sherry Williams for manuscript preparation and editorial support; Mary Gail Engle, B.S., for EM analysis. We also thank Dr. Deneys van der Westhuyzen for critically reading the manuscript.

\section{References}

Ancsin JB and Kisilevsky R (1999). The heparin/heparan sulfate-binding site on apo-serum amyloid A. Implications for the therapeutic intervention of amyloidosis. J Biol Chem 274:7172-7181.

Axelrad MA, Kisilevsky R, Willmer J, Chen SJ, and Skinner M (1982). Further characterization of amyloid-enhancing factor. Lab Invest 47:139-146.

Baumann H and Gauldie J (1990). Regulation of hepatic acute phase plasma protein genes by hepatocyte stimulating factors and other mediators of inflammation. Mol Biol Med 7:147-159.

Benditt EP and Ericksen N (1977). Amyloid protein SAA is associated with high density lipoprotein from human serum. Proc Natl Acad Sci USA 74:4025-4028.

Benson MD and Kleiner E (1980). Synthesis and secretion of serum amyloid $A$ (SAA) by hepatocytes in mice treated with casein. J Immunol 124:495-499.

Botto M, Hawkins PN, Bickerstaff MC, Herbert J, Bygrave AE, McBride A, Hutchinson WL, Tennent GA, Walport MJ, and Pepys MB (1997). Amyloid deposition is delayed in mice with targeted deletion of the serum amyloid $\mathrm{P}$ component gene. Nat Med 3:855-859.

Cathcart ES, Carreras I, Elliot-Bryant R, Liang JS, Gonnerman WA, and Sipe JD (1996). Polymorphism of acute-phase serum amyloid $A$ isoforms and amyloid resistance in wildtype Mus musculus czech. Clin Immunol Immunopathol 81:22-26.

Chiba T, Kogishi K, Wang J, Xia C, Matsushita T, Miyazaki J-I, Saito I, Hosokawa M, and Higuchi K (1999). Mouse senile amyloid deposition is suppressed by adenoviral-mediated overexpression of amyloid-resistant apolipoprotein A-II. Am J Pathol 155:1319-1326.

Coetzee GA, Strachan AF, van der Westhuyzen DR, Hoppe H, Jeenah MS, and de Beer FC (1986). Serum amyloid A-containing human high density lipoprotein 3. Density, size, and apolipoprotein composition. J Biol Chem 261:96449651.

Come JH, Fraser PE, and Lansbury PT (1996). A kinetic model for amyloid formation in prion diseases - importance of seeding. Proc Natl Acad Sci 90:5959-5963.

de Beer MC, de Beer FC, McCubbin WD, Kay CM, and Kindy MS (1993). Structural prerequisites for serum amyloid A fibril formation. J Biol Chem 268:20606-20612.

de Beer MC, Yuan T, Kindy MS, Asztalos BF, Roheim PS, and de Beer FC (1995). Characterization of constitutive human serum amyloid A protein (SAA4) as an apolipoprotein. J Lipid Res 36:526-534. 
Elliott-Bryant R, Liang JS, Sipe JD, and Cathcart ES (1996). Degradation of serum amyloid $A$ in amyloid-susceptible and amyloid-resistant mouse strains. Scand J Immunol 44:223228.

Engelhardt JF, Litzky L, and Wilson JM (1994). Prolonged transgene expression in cotton rat lung with recombinant adenoviruses defective in E2a. Hum Gene Ther 5:1217-1229.

Feinberg AP and Vogelstein B (1984). A technique for radiolabeling DNA restriction endonuclease fragments to high specific activity. Anal Biochem 137:266-267.

Gonnerman WA, Elliot-Bryant R, Carreras I, Sipe JD, and Cathcart ES (1995). Linkage of protection against amyloid fibril formation in the mouse to a single, autosomal dominant gene. J Exp Med 181:2249-2252.

Gonnerman WA, Kandel R, and Cathcart ES (1996). Amyloid enhancing factor is produced by rats and amyloid-resistant CE/J mice. Lab Invest 74:259-264.

Grunfeld C, Memon RA, Rapp JH, and Feingold KR (1992). Regulation of hepatic lipid metabolism by cytokines that induce the acute phase response. Folia Histochem Cytobiol 30:102-202.

Hoffman JS and Benditt EP (1982). Secretion of serum amyloid protein and assembly of serum amyloid protein-rich high density lipoprotein in primary mouse hepatocyte culture. J Biol Chem 257:10518-10522.

Kindy MS and de Beer FC (1999). A mouse model for serum amyloid A amyloidosis. Methods Enzymol 309:701-716.

Kindy MS, King AR, Perry G, de Beer MC, and de Beer FC (1995). Association of apolipoprotein $E$ with murine amyloid $A$ protein amyloid. Lab Invest 73:469-475.

Kindy MS, King AR, Yu J, Gerardot C, Whitley J, and de Beer FC (1998). Adenoviral expression of murine serum amyloid $A$ proteins to study amyloid fibrillogenesis. Biochem J 332:721728.

Kindy MS and Rader DJ (1998). Reduction in amyloid A amyloid formation in apolipoprotein-E-deficient mice. Am J Pathol 152:1387-1395.

Kisilevsky R (1996). Anti-amyloid drugs: Potential in the treatment of disease associated with aging. Drugs Aging 8:75-83.

Kisilevsky R, Lemieux LJ, Fraser PE, Kong X, Hultin PG, and Szarek WA (1995). Arresting amyloidosis in vivo using smallmolecule anionic sulphonates or sulphates: Implications for Alzheimer's disease. Nat Med 1:143-148.

Kluve-Beckerman B, Liepnieks JJ, Wang L, and Benson MD (1999). A cell culture system for the study of amyloid pathogenesis. Amer J Pathol 155:123-133.

Liang J, Elliot-Bryant R, Hajri T, Sipe JD, and Cathcart ES (1998). A unique amyloidogenic apolipoprotein serum amyloid A (apoSAA) isoform expressed by the amyloid resistant $\mathrm{CE} / \mathrm{J}$ mouse strain exhibits higher affinity for macrophages than apoSAA1 and apoSAA2 expressed by amyloid susceptible CBA/J mice. Biochim Biophys Acta 1394:1121-1126.

McAdam KPWJ and Sipe JD (1976). Murine model for human secondary amyloidosis: Genetic variability of the acutephase serum protein SAA response to endotoxins and casein. J Exp Med 144:1121-1127.

Meek RL, Hoffman JS, and Benditt EP (1986). Amyloidogenesis: One serum amyloid $A$ isotype is selectively removed from the circulation. J Exp Med 163:499-510.
Naiki H, Higuchi K, Hosokawa M, and Takeda T (1989). Fluorometric determination of amyloid fibrils in vitro using the fluorescent dye, thioflavin T1. Anal Biochem 177:244-249.

Patel H, Bramall J, Waters H, de Beer M, and Woo P (1996). Expression of recombinant human serum amyloid $A$ in mammalian cells and demonstration of the region necessary for high-density lipoprotein binding and amyloid fibril formation by site-directed mutagenesis. Biochem J 318:1041-1049.

Pepys MB and Baltz ML (1983). Acute phase proteins with special reference to C-reactive protein and related proteins (pentraxins) and serum amyloid A. Adv Immunol 34:141-212.

Pras M, Shubert M, Zucker-Franklin D, Rimon A, and Franklin E (1968). The characterization of soluble amyloid prepared in water. J Clin Invest 47:924-933.

Puchtler H and Sweat F (1965). Congo red as a stain for fluorescence microscopy or amyloid. J Histochem Cytochem 13:693-694.

Rokita H, Shirahama T, Cohen AS, and Sipe J (1989). Serum amyloid $A$ gene expression and $A A$ amyloid formation in $A / J$ and SJL/J mice. Br J Exp Pathol 70:327-335.

Shiroo M, Kawahara E, Nakanishi I, and Migita S (1987). Specific deposition of serum amyloid A protein 2 in the mouse. Scand J Immunol 26:709-716.

Sipe JD, Carreras I, Gonnerman WA, Cathcart ES, de Beer MC, and de Beer FC (1993). Characterization of the inbred $\mathrm{CE} / \mathrm{J}$ mouse strain as amyloid resistant. Amer $\mathrm{J}$ Pathol 143:1480-1485.

Sipe JD, McAdam KP, and Uchino F (1978). Biochemical evidence for the biphasic development of experimental amyloidosis. Lab Invest 38:110-114.

Sipe JD, Vogel SN, Sztein MB, Skinner M, and Cohen AS (1982). The role of interleukin 1 in acute phase SAA and SAP synthesis. Ann N Y Acad Sci 389:137-150.

Strachan AF, de Beer FC, van der Westhuyzen DR, and Coetzee GA (1988). Identification of three isoform patterns of human serum amyloid A protein. Biochem J 250:203-207.

Telling GC, Haga T, Torchia M, Tremblay P, DeArmond SJ, and Prusiner SB (1996). Interactions between wild-type and mutant prion proteins modulate neurodegeneration in transgenic mice. Genes Dev 10:1736-1750.

Tsukamoto K, Smith P, Glick JM, and Rader DJ (1997). Liver-directed gene transfer and prolonged expression of three major human ApoE isoforms in ApoE-deficient mice. $\mathrm{J}$ Clin Invest 100:107-114.

Vogel SN and Sipe JD (1982). The role of macrophages in the acute phase serum amyloid $A(S A A)$ response to endotoxin. Surv Immunol Res 1:235-241.

Webb NR, de Beer MC, van der Westhuysen DR, Kindy MS, Banka CL, Tsukamoto K, Rader DJ, and de Beer FC (1997). Adenoviral vector-mediated overexpression of serum amyloid A in apoA-1-deficient mice. J Lipid Res 38:1583-1590.

Westermark GT, Engstrom U, and Westermark P (1992). Biochem Biophys Res Commun 182:27-33.

Yamada T, Kluve-Beckerman B, Liepnieks JJ, and Benson MD (1994). Fibril formation from recombinant human serum amyloid A. Biochim Biophys Acta 1226:323-329. 